\title{
Review
}

\section{Adhesion strength of orthodontic brackets to acrylic surfaces. A systematic review on in vitro studies.}

\author{
Mónica Morado Pinho ${ }^{a, *}$, Maria Conceição Manso ${ }^{b, c}$, Conchita Martin ${ }^{d}$, \\ Júlio C. M. Souza ${ }^{e, f}$, Ricardo Faria Almeida ${ }^{g}$, Afonso Pinhão Ferreira ${ }^{g}$ \\ a School of Dentistry, School of Health Sciences (FCS), Universidade Fernando Pessoa (UFP), Porto, Portugal \\ ${ }^{b}$ Faculty of Health Sciences, FP-ENAS, University Fernando Pessoa, Porto, Portugal \\ c REQUIMTE, University of Porto, Portugal \\ d School of Dentistry, University Complutense of Madrid (UCM) \\ e Center for Microelectromechanical Systems (CMEMS), University of Minho, Guimarães, Portugal \\ $f$ Post-graduate Program in Dentistry (PPGO), Federal University of Santa Catarina (UFSC), Florianópolis/SC, Brazil \\ 9 School of Dentistry (FMDUP), University of Porto (UP), Porto, Portugal
}

\section{A R T I C L E I N F O}

\section{Article history:}

Received 10 March 2017

Accepted 13 July 2017

Available online 20 July 2017

\section{Keywords:}

Acrylic resin

Adhesion

Crowns

Dental bonding

Orthodontic brackets

Provisional material

\begin{abstract}
A B S T R A C T
\end{abstract}
Objectives: The aim of this study was to systematically review the available literature about in vitro orthodontic bond strength tests regarding bonding brackets to acrylic teeth.

Methods: A comprehensive electronic database search with no date or language limits was conducted. Relevant studies were selected based on predefined criteria: in vitro investigation on the shear/tensile bond strength of brackets evaluated and expressed in megapascals and/or considering the adhesive remnant index; and studies with a clear explanation of the bonding technique/protocol, bonding materials and type of surface acrylic material used.

Results: 2044 published articles were presented by the four databases. Of the studies collected from all the databases, 28 based on their title and 14 based on their abstract, only 10 studies fulfilled the selection criteria after being examined twice by the two reviewers.

Conclusion: The type of surface noticeably influenced the adhesion, and surface treatments should be performed to improve bond strength. (Rev Port Estomatol Med Dent Cir Maxilofac. 2017;58(2):65-70)

(C) 2017 Sociedade Portuguesa de Estomatologia e Medicina Dentária. Published by SPEMD. This is an open access article under the CC BY-NC-ND license (http://creativecommons.org/licenses/by-nc-nd/4.0/).

\footnotetext{
* Corresponding author.

E-mail address: monicap@ufp.edu.pt (Mónica Morado Pinho).

http://doi.org/10.24873/j.rpemd.2017.07.020

1646-2890/@ 2017 Sociedade Portuguesa de Estomatologia e Medicina Dentária. Published by SPEMD.

This is an open access article under the CC BY-NC-ND license (http://creativecommons.org/licenses/by-nc-nd/4.0/).
} 


\title{
Adesão de brackets ortodônticos a superficies acrílicas. Uma revisão sistemática sobre estudos in vitro.
}

\author{
R E S U M O
}

\section{Palauras-chave:}

Resina acrilica

Adesão

Coroas

Colagem

Brackets ortodônticos

Material provisório
Objetivos: O objetivo deste estudo foi efetuar uma revisão sistemática da literatura sobre testes in vitro de resistência à adesão entre brackets ortodônticos e dentes acrílicos.

Métodos: Foi realizada uma pesquisa abrangente em bases electrónicas, sem limites de data ou idioma. Os estudos relevantes foram selecionados com base nos seguintes critérios pré-definidos: investigação in vitro sobre resistência ao cisalhamento/tração dos brackets avaliada e apresentada em megapascais e/ou considerando o índice de adesivo remanescente; estudos com explicação clara da técnica/protocolo de adesão, adesivos e tipo de material acrílico das superfícies.

Resultados: dos 2044 artigos publicados apresentados pelas quatro bases de dados electrónica, 28 foram selecionados com base no título e $14 \mathrm{com}$ base no resumo. Apenas 10 obedeceram aos critérios definidos e foram incluídos após análise por dois revisores, duas vezes.

Conclusão: O tipo de superfície parece influenciar a adesão e o tratamentos destas deve ser realizado para melhorar a adesão. (Rev Port Estomatol Med Dent Cir Maxilofac. 2017;58(2):65-70)

(C) 2017 Sociedade Portuguesa de Estomatologia e Medicina Dentária. Publicado por SPEMD. Este é um artigo Open Access sob uma licença CC BY-NC-ND (http://creativecommons.org/licenses/by-nc-nd/4.0/).

\section{Introduction}

Nowadays, the strategy of bonding brackets to acrylic resin surfaces is often applied in the cases of patients with provisional prosthetic structures. However, the bond strength between bracket, adhesive and synthetic surfaces is still a concern during the orthodontic treatment. Additionally, bond failure of brackets during orthodontic treatment has a timecost impact and leads to patient inconvenience. ${ }^{1}$

Provisional crowns of Bis-acrylic resins are methyl methacrylate resins enhanced with glass particles for a higher mechanical resistance. ${ }^{2,3,4} \mathrm{~A}$ chemical and mechanical adhesion should be performed to bond orthodontic brackets to those materials. For that reason, different bonding protocols are described in the literature. ${ }^{4,5}$

As known, in vivo testing in controlled trials would be the best way to evaluate the effectiveness of protocols. ${ }^{6}$ However, in vivo tests on bonding brackets to provisional teeth during orthodontic treatment are scarce or even null in the literature.

In vitro studies possibly allow the use of more standardised procedures for testing a specific bonding system. However, there is a great diversity of experimental conditions used for bond strength testing. ${ }^{1}$

The aims of this study were to systematically review the available literature about in vitro orthodontic bond strength tests regarding bonding brackets to acrylic teeth and to analyse which materials and technique/protocol present the highest success rate.

\section{Methods}

Published in vitro studies on orthodontic bond strength tests regarding bonding orthodontic brackets to acrylic teeth were included. No date or language limits were implemented.

A comprehensive electronic database search with no date or language limits was conducted, and references in relevant articles were searched manually for additional literature. Also, the search was not restricted to any type of study design.

The following electronic databases were searched: MEDLINE, PubMed, ClinicalKey, Lilacs and Web of Science. The search strategy was focused on the following terms: 'orthodontic bracket', 'acrylic resins', 'crowns', 'dental bonding', 'provisional material', 'provisional crown*' and 'acrylic*'. MeSH terms were used in the PubMed database (Table 1).

To be included in the review, the studies had to meet the following selection criteria: in vitro investigation on the shear (SBS) or tensile (TBS) bond strength of orthodontic brackets evaluated and expressed in megapascals (MPa) and/or on the adhesive remnant index (ARI); and studies with a clear explanation of the bonding technique/protocol, the bonding materials and the type of surface acrylic material used.

Two reviewers independently screened the titles of the retrieved records, and those related to bond strength between the orthodontic bracket and acrylic surfaces were included. The abstracts of the selected publications were read. When an abstract was considered relevant by at least one author, the corresponding article was read. On a second stage, full-text articles of relevant studies were obtained for eligibility and analysed consid- 
Table 1. Search strategy

\begin{tabular}{|c|c|c|c|}
\hline & Keywords/MeSH terms & Literature search strategy & Database \\
\hline 1 & 'orthodontic brackets' [Mesh] & \multirow{4}{*}{$\begin{array}{l}\# 1 \text { AND \#3 } \\
\# 1 \text { AND \#5 } \\
\# 1 \text { AND \#3 AND \#8 } \\
\# 1 \text { AND \#5 AND \#8 }\end{array}$} & \multirow{4}{*}{ Pubmed } \\
\hline 2 & bracket* & & \\
\hline 3 & crowns' [Mesh] & & \\
\hline 4 & crown* & & \\
\hline 5 & 'acrylic resins' [Mesh] & \multirow{4}{*}{$\begin{array}{l}\# 2 \text { AND } 4 \\
\# 2 \text { AND \#6 } \\
\# 2 \text { AND \#7 }\end{array}$} & \multirow{4}{*}{ ClinicalKey / Lilacs / WOS } \\
\hline 6 & acrylic* & & \\
\hline 7 & provisional material* & & \\
\hline 8 & 'dental bonding' [Mesh] & & \\
\hline
\end{tabular}

\#, Search; Mesh, medical subjects heading ; *, truncation of a text word; WOS, Web of Science

ering the purpose of the present study. The articles of abstracts with not enough relevant information were also obtained. The references of relevant publications were hand-searched, and all articles containing the words 'bond' and 'acrylic' together with 'brackets' were selected as additional relevant publications that could have been missed by the search engines. Book chapters, abstracts, letters and reviews were excluded since the aim of this systematic review was to evaluate primary studies.

The experimental conditions were categorised in a list of 34 items. The two reviewers discussed those items before reading the full text in order to reach an agreement about the items to include. During the full articles reading, the reviewers independently assessed whether the experimental conditions were reported in the study. Moreover, to minimise bias, the two observers independently evaluated the validity of original studies and read them twice in different times and sequences.

\section{Results}

The results of this review were described narratively. The search results and the initial number of published studies presented by the various databases are provided in Figure 1. Of the studies collected from all the databases, 28 based on their title and 14 based on their abstract, only 10 studies fulfilled the selection criteria after being individually examined twice by the two reviewers. Two of the trials were rejected: one because it was decided to definitely not include polycarbonate crowns as acrylic ones after reviewers' discussion, and the other because its authors showed bond strength values in Newtons (N) rather than megapascals (MPa).

The experimental conditions for in vitro tests are shown in Table 2. The selected studies on acrylic surfaces revealed no data on tensile bond strength and, besides the inclusion criteria items, the surface treatment and the crosshead speed were the most frequently reported conditions for the shear bond test $(100 \%)$. Within the 10 selected studies, factors related to brackets and samples storage were the second most relevant ones.

The 10 selected articles were categorised by topics, according to the type of acrylic surface $(n=5)$, type of surface treatment $(n=7)$, type of adhesive $(n=5)$ and ageing samples protocols $(n=3)$ used. The aims and main results, as well as the statistical meth-

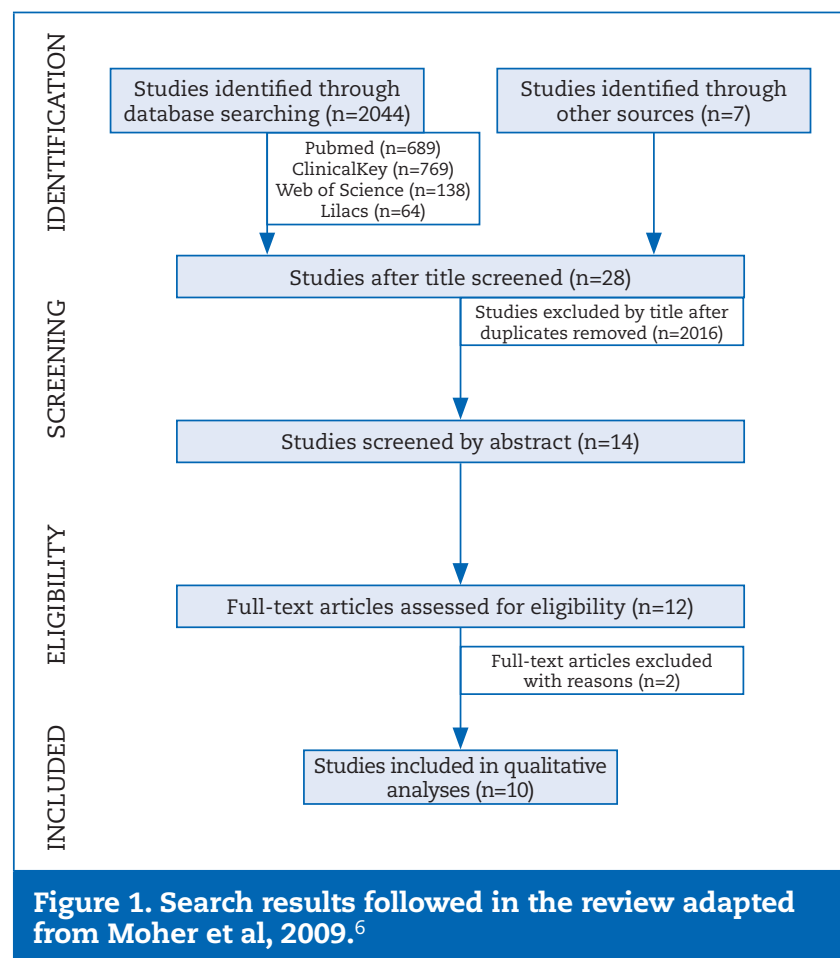

ods of all 10 studies, are presented in Appendix 1. The variables relevant to bond strength and the bond strength mean values were summarised in Appendixes 2 and 3.

Type of acrylic surface $(n=5)$. Of the five publications considering different surfaces for orthodontic brackets bonding, two evaluated five different temporary crown materials, one evaluated four and two evaluated three different materials. All studies ${ }^{2,4,5,7,8}$ included at least one group of bis-acryl/bis-GMA ${ }^{2,4,5,7,8}$ composite resins and one of an acrylic resin based on methacrylate (MMA), ${ }^{4}$ polymethyl methacrylate (PMMA $)^{2,5,7,8}$ or poly ethyl methacrylate (PEMA). 2,4,7 One also included a resin based on urethane dimethacrylate (UDMA). ${ }^{7}$ All studies performed shear bond tests and presented the mean results in MPa. Three revealed a significant influence of the surface type on the bond strength of orthodon- 


\section{Table 2. Experimental conditions}

\begin{tabular}{|c|c|c|}
\hline \multirow{2}{*}{$\begin{array}{l}\text { Experimental condition } \\
\text { Substrate origin }\end{array}$} & \multicolumn{2}{|c|}{$\begin{array}{l}\text { Number / \% of studies } \\
\text { reporting the experimental } \\
\text { condition }\end{array}$} \\
\hline & 10 & 100 \\
\hline Acrylic composition description & 4 & 40 \\
\hline Surface treatment & 10 & 100 \\
\hline $\begin{array}{l}\text { Surfaces storage time before } \\
\text { bonding }\end{array}$ & 1 & 10 \\
\hline $\begin{array}{l}\text { Surfaces storage temperature before } \\
\text { bonding }\end{array}$ & 1 & 10 \\
\hline $\begin{array}{l}\text { Surfaces storage solution before } \\
\text { bonding }\end{array}$ & 1 & 10 \\
\hline Bracket material & 8 & 80 \\
\hline :: metal & 8 & 80 \\
\hline :: ceramics & 1 & 10 \\
\hline Bracket area & 5 & 50 \\
\hline Type of bracket & 8 & 80 \\
\hline Type of etchant & 8 & 80 \\
\hline Time of etching & 7 & 70 \\
\hline Adhesive type & 10 & 100 \\
\hline $\begin{array}{l}\text { Amount of force at bracket } \\
\text { placement }\end{array}$ & 3 & 30 \\
\hline Light device type & 6 & 60 \\
\hline Total polymerization time & 6 & 60 \\
\hline Light directions & 4 & 40 \\
\hline Sample storage time & 9 & 90 \\
\hline Sample storage solution & 8 & 80 \\
\hline Sample storage temperature & 8 & 80 \\
\hline Thermocycling & 3 & 30 \\
\hline Thermocycling cycles & 3 & 30 \\
\hline $\begin{array}{l}\text { Thermocycling water baths } \\
\text { temperature }\end{array}$ & 2 & 20 \\
\hline Shear testing as test method & 10 & 100 \\
\hline Tensil testing as test method & 0 & 0 \\
\hline Bond strength in $\mathrm{MPa}$ & 10 & 100 \\
\hline Crosshead speed & 10 & 100 \\
\hline ARI & 5 & 50 \\
\hline $\begin{array}{l}\text { Magnification used in determining } \\
\text { ARI }\end{array}$ & 5 & 50 \\
\hline Failure mode & 4 & 40 \\
\hline Surface roughness & 1 & 10 \\
\hline SEM & 2 & 20 \\
\hline
\end{tabular}

Inclusion criteria tic metal ${ }^{2,4,5}$ and ceramic brackets. ${ }^{4}$ One also found significant differences between the surface materials, but an interaction of variables made results unable to be interpreted. ${ }^{8}$ One study stated that the surface type did not influence bond strength. ${ }^{7}$

Type of surface treatment $(n=7)$. Four studies evaluated three different surface treatments, , 2,5,7,9 two evaluated two pre-treatments ${ }^{10,11}$ and one analysed 14 groups all with different substrate treatments. ${ }^{12}$ The surface treatments applied were the following: none (control), ${ }^{5,12}$ polished with greenstone, ${ }^{5}$ sandblasted, $, 5,5,9,11,12$ silane, ${ }^{12}$ diamond bur, ${ }^{10,11,12} 9.6 \%$ hydrofluoric acid, ${ }^{12} 37 \%$ phosphoric acid,, 12 monomer, ${ }^{2,12}$ plastic conditioner, ${ }^{12}$ silica carbide paper, ${ }^{2,9}$ pumice polishing paste, ${ }^{2}$ pumice and rubber cup ${ }^{10}$ and Laser Er:YAG. ${ }^{7}$ Sandblasting with $50-\mu \mathrm{m} \mathrm{Al}_{2} \mathrm{O}_{3}$ particles was performed in test groups of six studies. One study used a diamond bur not to grid the acrylic but to create a window in order to enhance the mechanical adhesion. ${ }^{11}$ All studies performed shear bond tests and presented the mean results in $\mathrm{MPa}$. Five studies identified bond strength as being influenced by the surface treatment protocols. ${ }^{2,5,7,9,11}$ One study related a higher roughness to an increase in the bond strength. ${ }^{12}$ Another study also indicated that bond strength was influenced by the surface treatment but only for the light-cure composite resin. ${ }^{10}$

Type of adhesive $(n=5)$. Three articles reported a comparison between the use of an acrylic resin and a light-cure composite resin and between a bond metal bracket and an acrylic surface..$^{2,10,13}$ One article compared a composite resin with a cyanoacrylate adhesive and Panavia ${ }^{\mathrm{TM}}$ used in different protocols. ${ }^{11}$ Another study evaluated the adhesion of a resin-reinforced glass ionomer to metal and ceramic brackets and of a composite resin to acrylic substrates. ${ }^{4}$ Bond strength was reported after shear bond strength tests in MPa and was shown to be influenced by the type of adhesive in four articles. ${ }^{2,10,11,13}$ Only one study showed no influence of the adhesives on bond strength. ${ }^{4}$

Ageing samples protocols $(n=3)$. Three studies evaluated the influence of thermocycling fatigue tests on bond strength. $2,7,11$ Two of them presented information on the number of cycles, the temperature of the solution and the dwell time between baths., ${ }^{2,7}$ One mentioned only the number of thermal cycles. ${ }^{11}$ All studies performed 500 cycles of thermocycling fatigue tests to age the study samples. $2,7,11$ The shear bond strength was presented in $\mathrm{MPa}$ and reported contradictorily by authors regarding its association with the thermocycling. One study stated an influence of thermocycling on adhesiveness, ${ }^{2}$ other did not ${ }^{11}$ and the third indirectly suggested that influence. ${ }^{7}$ In one study, the samples were aged by storing them in distilled water at $35^{\circ} \mathrm{C}$ for a week and the evaluation groups were stored for a whole month. ${ }^{5}$

Other relevant variables

- Adhesive remnant index (ARI) and failure mode. The adhesive remnant index, firstly described by Artun and Bergland (1984), ${ }^{14}$ was used in five studies $2,5,8,9,10$ to categorise the amount of adhesive remaining on the substrate $2,5,8,9$ and/or determine the adhesion failure mode. ${ }^{5,9}$ Three studies used the ARI only for categorisation. Of those, one found an inconsistent pattern but did not draw any conclusions based on that, ${ }^{8}$ and other only described the clinical situation by 
discussing the limitations of the ARI to characterise the fracture. ${ }^{2}$ Those two studies did not associate the ARI to bond strength or surface. However, the third one found a qualitative association between the ARI score and the effectiveness of bracket/acrylic surface bond, and not a direct association with the amount of bond strength or the bond failure mode. ${ }^{10}$ One study ${ }^{5}$ determined the adhesion failure mode and showed different failure modes in PMMA (adhesive failures independently of storage time) and bis-acryl (adhesive and cohesive failures at one-week storage and mostly cohesive failure at one-month storage). Moreover, only one study associated a reduction in bond strength with an interface temporary crown/adhesive failure. ${ }^{9}$ The failure mode was reported by one article without index categorisation and was found to be adhesive failure type in all specimens. ${ }^{4}$

- Surface roughness / Scanning Electron Microscopy (SEM). Two studies evaluated the surface roughness using scanning electron microscopy (SEM) after different acrylic surface treatments. One performed a quantitative analysis $^{12}$ and the other a qualitative analysis. ${ }^{7}$ One study stated that the diamond bur created the highest roughness on the acrylic followed by sandblasting, and that etching and monomer or plastic conditioner applications resulted in scarce acrylic alterations. ${ }^{12}$ The other publication only described the appearance of the surfaces after three different surface treatments. ${ }^{7}$

- Storage time and solution. Storage methods were mentioned in all publications, except for one. ${ }^{13}$ Eight studies $^{2,4,5,7,8,9,10,12}$ presented the storage time and solution and one only the storage time. ${ }^{11}$

- Crosshead speed. The included data showed the use of diverse crosshead speeds in shear tests, namely, $0.5 \mathrm{~mm} /$ $\min ,{ }^{5,9,10,12,13} 1 \mathrm{~mm} / \mathrm{min}^{2,7,8,11}$ and $5 \mathrm{~mm} / \mathrm{min}^{4}$

\section{Discussion}

Great diversity was noticed in the experimental conditions for bond strength testing. This situation had already been stated in the literature for orthodontic brackets adhesion to enamel ${ }^{1}$ and ceramics. ${ }^{14}$ In the literature search performed by the authors, no systematic review about the present issue was found. Therefore, it was assumed that this would be the first systematic review on the bond strength of orthodontic brackets to provisional acrylic materials. However, a great diversity of experimental conditions on this issue was noticed, and, because of that lack of standardisation, the studies could only be evaluated individually. ${ }^{1}$

Even though the comparison between different methods cannot be performed, the results can predict the mechanical strength of the bracket to acrylic interfaces if factors are considered separately.

Clinically acceptable shear bond strength values were stated to be higher than $5.9 \mathrm{MPa} \cdot{ }^{15}$ However, bond strength to acrylic provisional materials revealed values ranging from 0 $\mathrm{MPa}^{2}$ to $19.82 \pm 2.93 \mathrm{MPa},{ }^{11}$ depending on some factors. For instance, the type of surface, ${ }^{2,4,5}$ the treatment, $2,5,7,9,11$ the type of adhesive $9,10,11,13$ and the thermal cycling ${ }^{2,7}$ were found to cause differences in shear bond strength values.
Considering similar surfaces subjected to the same surface treatment (sandblasting) and adhesive (light-cured bis-GMAbased composite resin), bis-acrylic surfaces showed bond strength mean values ranging from $3.75 \pm 0.08 \mathrm{MPa} 5$ to 13.1MPa. ${ }^{2}$ Some studies ${ }^{5,7}$ obtained mean values that were not clinically acceptable. On the other hand, one study2 found higher values, which seems to be related to the type of surface since it may provide a chemical cross-link with the bifunctional acrylates present on it. The better performance after thermocycling could also be explained by the same reason. In addition, the authors reported the influence of the surface treatment on the obtained results.

Sandblasting was evaluated as a surface treatment by other studies on this and other surfaces. 5,7,9,11,12 This type of surface treatment showed to enhance more the adhesive strength than other surface treatments like sandpaper $\mathrm{SiC}, 2,9$ monomer, ${ }^{9}$ etching ${ }^{7,12}$ and diamond bur. ${ }^{12}$ Laser Er:YAG irradiation caused an even greater increase in bond strength in a study ${ }^{7}$ where authors used SEM to determine the surface roughness after different surface treatments but did not conduct any comparative description of the type of surface material used. Other authors ${ }^{5}$ measured the surface roughness after different acrylic surface treatments. Results showed that the diamond bur created the highest roughness on the acrylic, followed by sandblasting, and that etching and monomer or plastic conditioner applications resulted in scarce acrylic alterations. ${ }^{5}$

Bond strength was also influenced by the type of adhesive. $9,10,11,13$ Acrylic resins performed better than composite resins and the presence of cyanoacrylate enhanced both materials' performance. This finding reinforces the idea that there is a chemical bond important to increase the bond strength of brackets to acrylic surfaces.

According to the obtained results, it seems plausible to suggest that the chemical strength between the type of surface and adhesive, as well as the mechanical strength provided by the surface treatment, should be considered as intervening factors in the deficit adhesion to provisional acrylic surfaces.

The results regarding the influence of thermocycling presented contradictory data. ${ }^{2,7,11}$ However, it is still considered as the reference technique for simulating ageing in the mouth environment. ${ }^{16}$

Since this review was on in vitro studies, other factors were considered important for bond strength, such as samples storage and crosshead speed. This is in agreement with a similar study conducted on the bond strength of brackets to enamel. ${ }^{1}$ All the included publications provided storage methods, except for one study that performed the shear test immediately after the brackets bonding to the surfaces. In most studies, the samples were kept in distilled water during at least one day at $37^{\circ} \mathrm{C} .^{2,4,5,7-10,12}$ Only in one study was the storage time longer since it was one of the variables in the study and considered to be an important factor. 5

Crosshead speed has been controversially reported in the literature. Its influence on the adhesion between brackets and enamel ${ }^{1,17}$ or ceramics ${ }^{18}$ was reported in some papers. On the other hand, other studies showed no influence. ${ }^{19,20}$ Little or no data was found regarding the influence of crosshead speed on acrylic surfaces. Even though the included studies used different crosshead speeds, $2,4,5,7-13$ none discussed this factor. 


\section{Conclusions}

Considering the limitations involved in the present literature review, related to different methods used to assess the bond strength of brackets to provisional surfaces and the type of studies considered (in vitro), only indications can be drawn. Low values of bond strength were observed for acrylic substrates. Some studies reported shear bond strength values below the clinically acceptable level. The type of surface seems to influence the adhesion of brackets. Surface treatments should be performed to improve the bond strength, and sandblasting or laser irradiation should be considered. The type of adhesive should be evaluated before bonding, to consider the ones that improve the chemical adhesion for brackets to bond to provisional acrylic surfaces.

The indications of the present study should be carefully analysed and their extrapolation to the clinical practice should take into account that they were drawn based on a review of in vitro studies.

\section{Ethical disclosures}

Protection of human and animal subjects. The authors declare that no experiments were performed on humans or animals for this study.

Confidentiality of data. The authors declare that no patient data appear in this article.

Right to privacy and informed consent. The authors declare that no patient data appear in this article.

\section{Conflict of interest}

The authors have no conflicts of interest to declare.

\section{Acknowledgments}

The author M.C. Manso acknowledges Fundação para a Ciência e a Tecnologia through grant UID/Multi/04546/2013 and UID/ QUI/50006/2013 - POCI/01/0145/FERDER/007265.

\section{Appendices}

Supplementary content Supplementary data associated with this article can be found, in the online version, at http://doi. org/10.24873/j.rpemd.2017.07.020.

\section{R E F E R E N C E S}

1. Finnema KJ, Ozcan M, Post WJ, Ren Y, Dijkstra PU. In-vitro orthodontic bond strength testing: a systematic review and meta-analysis. Am J Orthod Dentofacial Orthop. 2010;137:615-22.

2. Al Jabbari YS, Al Taweel SM, Al Rifaiy M, Alqahtani MQ, Koutsoukis T, Zinelis S. Effects of surface treatment and artificial aging on the shear bond strength of orthodontic brackets bonded to four different provisional restorations. Angle Orthod. 2014;84:649-55.

3. Gratton DG, Aquilino SA. Interim restorations. Dent Clin North Am. 2004;48:487-97.

4. Rambhia S, Heshmati R, Dhuru V, Iacopino A. Shear bond strength of orthodontic brackets bonded to provisional crown materials utilizing two different adhesives. Angle Orthod. 2009;79:784-9.

5. Chay SH, Wong SL, Mohamed N, Chia A, Yap AU. Effects of surface treatment and aging on the bond strength of orthodontic brackets to provisional materials. Am J Orthod Dentofacial Orthop. 2007;132:577.e7-11.

6. Moher D, Liberati A, Tetzlaff J, Altman DG. The PRISMA Group. Preferred reporting items for systematic reviews and meta-analyses: the PRISMA statement. J Clin Epidemiol. 2009;14:1006-12.

7. Goymen M, Topcuoglu T, Topcuoglu S, Akin H. Effect of different temporary crown materials and surface roughening methods on the shear bond strengths of orthodontic brackets. Photomed Laser Surg. 2015;33:55-60.

8. Maryanchik I, Brendlinger EJ, Fallis DW, Vandewalle KS. Shear bond strength of orthodontic brackets bonded to various esthetic pontic materials. Am J Orthod Dentofacial Orthop. 2010;137:684-9.

9. de Almeida JX, Deprá MB, Marquezan M, Retamoso LB, Tanaka O. Effects of surface treatment of provisional crowns on the shear bond strength of brackets. Dental Press J Orthod. 2013;18:29-34.

10. Dias FM, Pinzan-Vercelino CR, Tavares RR, Gurgel Jde A, Bramante FS, Fialho MN. Evaluation of an alternative technique to optimize direct bonding of orthodontic brackets to temporary crowns. Dental Press J Orthod. 2015;20:57-62.

11. Soon HI, Gill DS, Jones SP. A study to investigate the bond strengths of orthodontic brackets bonded to prosthetic acrylic teeth. J Orthod. 2015;42:192-9.

12. Masioli DLC, Almeida MAO, Masioli MA, Almeida JRM. Assessment of the effect of different surface treatments on the bond strength of brackets bonded to acrylic resin. Dental Press J Orthod. 2011;16:37-47.

13. Correia AMO, Jóia RP, Rode SM, Repek CE, Mendonça AAM, Paranhos LR. Bonding orthodontic braces in acrylic resin with cyanoacrylate: does it improve adesion? Matéria (Rio J.) 2016;21:235-42.

14. Artun J, Bergland S. Clinical trials with crystal growth conditioning as an alternative to acid-etch enamel pretreatment. Am J Orthod. 1984;85:333-40.

15. Grewal Bach GK, Torrealba Y, Lagravère MO. Orthodontic bonding to porcelain: a systematic review. Angle Orthod. 2014;84:555-60.

16. Reynolds IR. A review of direct orthodontic bonding. Br J Orthod. 1975;2:171-8.

17. Eliades $\mathrm{T}$, Bourauel C. Intraoral aging of orthodontic materials: the picture we miss and its clinical relevance. Am J Orthod Dentofacial Orthop. 2005;127:403-12.

18. Bishara SE, Soliman M, Laffoon J, Warren JJ. Effect of changing a test parameter on the shear bond strength of orthodontic brackets. Angle Orthod. 2005;75:832-5.

19. Abdelnaby YL. Effects of cyclic loading on the bond strength of metal orthodontic brackets bonded to a porcelain surface using different conditioning protocols. Angle Orthod. 2011;81:1064-9.

20. Sood A, Ramarao S, Carounanidy U. Influence of different crosshead speeds on diametral tensile strength of a methacrylate based resin composite: An in-vitro study. J Conserv Dent. 2015;18:214-7.

21. Klocke A, Kahl-Nieke B. Influence of cross-head speed in orthodontic bond strength testing. Dent Mater. 2005;21:139-44. 